\title{
Student Perspectives on the Role of the Instructor in Face-to-Face and Online Learning
}

\author{
A. Després-Bedward, T. L. Avery, and K. Phirangee
}

\begin{abstract}
Due to the flexibility of online learning, it has grown in popularity over the years. However, online learning experiences high attrition rates and an increase of dissatisfaction among students. This dissatisfaction has been linked to the supports students receive for their learning. The goal of the current research is to develop a better understanding of how instructors can provide and facilitate better online learning support to increase student satisfaction. Five undergraduate students from a North American online university were interviewed to explore their perceptions around the effects of support on their relationship to their studies. Our research identified four main themes that influenced student levels of satisfaction which include: instructor service and support, student attitude, auxiliary support, and course design and setup. Overall, the findings revealed that the timeliness and consistent involvement of the instructor had a positive impact on student satisfaction.
\end{abstract}

Index Terms-Computer-supported learning, support tools, distance education, student support.

\section{INTRODUCTION}

With the advancement of technology, learning has evolved from an informal environment, to a structured curriculum delivered in one physical location, to what is now known as distance learning. Distance learning originated in Canada in 1888 when students used correspondence to complete courses at Queen's University [1]. When we talk about distance learning now, we are often referring to online learning. Recent trends suggest that online learning will only grow in popularity and that the hesitation by some to use it as a source of education stems from the lack of support provided by online institutions in the past [2]-[4].

Universities with a traditional face-to-face campus approach generally have the advantage of setting up offices where students may walk in if they need more support. On the other side of the spectrum, universities that specialize in online learning are generally bound to operate differently because of their limited modes of communication [5]. Online universities rely more on telecommunications and the Internet [6], thus often more readily equipping students to

Manuscript received November 30, 2017; revised May 15, 2018. This research was supported by the Social Sciences and Humanities Research Council of Canada.

The authors are with the Ontario Institute for Studies in Education, University of Toronto, Toronto, ON, Canada (e-mail: antoine.despres.bedward@mail.utoronto.ca,

Teresa.avery@mail.utoronto.ca).

Krystle Phirangee is with Ryerson University, Toronto, ON, Canada (e-mail: kphirangee@ryerson.ca). resolve problems without the in-person contact relied upon by traditional face-to-face institutions [5].

The faculty of a university also plays a vital role in a student's experience [2], [5], [7]. Program development and offerings of online courses by postsecondary institutions increased steadily over the last two decades and are growing at a significantly higher rate than the traditional post-secondary course offerings [5]. The increase in online course offerings may have an impact on the time faculty have to provide attention to individual students.

With the increase in enrollment of students in online universities, understanding the importance of student satisfaction is critical. Currently, the growth of a diverse demographic at public universities and colleges has students demanding that instructors provide equally diverse learning opportunities and supports [3]. Many factors, such as learner autonomy and course structure, influence student satisfaction. However, support offered by the university instructors seems to have the greatest impact on student satisfaction and learning outcomes. For instance, Moore [8] argued that successful teaching at a distance depends on the institution and the instructor providing the appropriate opportunities for dialogue between teacher and learner. Online learning also requires similar varied opportunities for dialogue between teacher and learner. Umbach \& Wawryznski [9] and Yilmaz \& Keser [6] emphasized similarly how instructors influence student satisfaction. They stated students feel supported and are more active participants in institutions where faculty engaged with them in and out of the classroom, placing a high priority on enriching educational experiences. Determining the variables that influence positive and negative attitudes towards online learning allow researchers and administrators to be more informed around the strategies that enhance student satisfaction levels and overall program quality [2]: these considerations are key as the least satisfied students come from online universities. When students are dissatisfied with online learning and its associated characteristics, they report negative emotions, such as being stressed about their online experience [2]. Previous research [10]-[12] has suggested that the absence of social cues in online courses makes it more difficult for students to communicate with each other, compared to face-to-face courses. The dependency on face-to-face interaction may cause some students to struggle with online dialogue: often students are unfamiliar with the online learning environment and are unaware of appropriate online communication methods.

When possible, instructors within universities must ensure that learners are provided with the learning materials, direction and tools necessary to succeed [8]. These integral supports are necessary to help students to develop a stronger 
sense of support and affiliation with their university. This sense of connectedness can have a positive impact on student motivation and satisfaction [7], [13]. Student satisfaction is linked to student enrollment and success, student retention, instructor involvement in online learning, and program development and quality [2].

When students are supported properly in an online learning setting, they report a more positive experience, and as a result they hold a higher regard for the learning tasks and the course content [2]. The purpose of this research study was to explore and compare the level of satisfaction of student support in two types of higher-learning environments: online and face-to-face. Specifically, the following research question was explored:

- How do students feel about the support provided to them in a face-to-face university and an online university?

For this study, satisfaction refers to the quality of a service or experience that is deemed adequate by the participant [2]. This study was conducted with students from one major North American University who had previous experiences of participating in a face-to-face and an online university. The study aimed to explore the students' level of satisfaction with both online and face-to-face learning as well as the attitude of students towards both learning environments. Understanding student satisfaction within these environments will not only help instructors in course design, but will enable both face-to-face and online universities to better address students' learning needs as well as contribute to making public tertiary education more accessible and inclusive.

\section{LITERATURE REVIEW}

As the competition for employment in Canada continues to increase, the number of students enrolling in university will also increase [14]. Students continue to invest in post-secondary education hoping that their hard work and their time spent will afford them the skills, knowledge and abilities to better compete in the working world. Keeping this investment in mind, universities are exploring new ways to increase their attraction of prospective students to their institution. At the same time, universities must accommodate for the increase in demand for flexible study without compromising the quality of services and support offered to their students. This accommodation involves taking into consideration the following: "As the distance education field matures it is to be hoped that greater attention will be paid to variables besides the communication media, especially the design of courses and the selection and training of instructors and the learning styles of students" [8]. The term distance education field can be replaced with the term online learning field in the quotation above. Student satisfaction is an important area of discussion related to the maturation process of the online learning environment. The effort placed on improving student satisfaction is in the best interests of both the online learning and traditional face-to-face institutions. The lack of satisfaction may have considerable repercussions: student attrition, hesitation to enroll in future programs and an overall lack of student participation [15].

Although many factors influence student satisfaction, support offered by the university faculty may have the greatest impact. In online universities, the transactional distance, which relates to cognitive space between instructors and learners in an educational setting, has a great impact on the student [2]. Umbach \& Wawryznski [9] state that "institutions where faculty engage students in and out of the classroom and place a high priority on enriching educational experiences had students who felt supported and were active participants in their learning." By determining which variables influence positive and negative attitudes towards online learning, researchers and administrators may become more informed regarding strategies to enhance student satisfaction levels and program quality [2]. More research on this topic would inform students about the possible advantages that certain university delivery methods have when compared to others. The literature reviewed highlights the areas of need and indicates possible problem areas for students. Definitely, a lack of knowledge may contribute to the hesitation of students' willingness to try new forms of education such as online learning. Moore [8] noted that "when a program is highly structured and teacher-learner dialogue is non-existent the transactional distance between learners and teachers is high." Adding to the importance of the students' experience, Palmer [2] stated that when students were dissatisfied with online learning and its associated characteristics, they reported negative emotionality and stressed more about their online experience. Therefore, if the opposite paradigm is assumed, satisfied students come from online learning institutions with low levels of transactional distance, those which offer sufficient opportunities for useful dialogue and which encourage positive student experiences.

The Perception of Support. The term support refers to giving active help and encouragement [16]. Throughout the review of the literature, support in an educational context tends to manifest itself in a variety of different ways on a variety of different levels. Jacklin \& Le Riche [17] note "sometimes the term 'student support' is used to refer to a very specific aspect of support." In their example, a search of 'student support' using a reputable search engine brought up the area of financial support. In addition to financial support, support in a higher education context can relate to learner support from the faculty. The encompassing characteristic of the use of the term support is that the student tends to encounter a problem and needs help from the services provided by the university [2].

Student support also involves maintaining a level of student interest, and stimulating intrinsic motivation: "having planned or been given a curriculum, a program of content to be taught, course instructors must stimulate, or at least maintain, the student's interest in what is to be taught, to motivate the student to learn, to enhance and maintain the learner's interest, including self-motivation" [7]. This paradigm suggests that student support extends beyond the initial registration phase and class introduction. The trend that the student demographic will continue to grow in numbers and in diversity reiterates the fact that universities will need to be proactive and adaptable to their service [2], [14]. Tait [18] identifies a series of three main functions of support which include cognition (supporting learning), affection (ensuring a supportive environment) and systemic (ensuring effective administrative services). The effort and 
delivery in these three areas are responsible for increasing the level of student satisfaction in both online and face-to-face universities, as well as for reducing transactional distance in learning institutions [7]. Jacklin \& Le Riche [17] discuss the idea of including students in the responsibility of providing support to fellow students as a strategy to meet the increase demand and complexity for additional supports. The dependency on students to provide support would require models that could be easily reproduced year after year, class after class to ensure the support needs are met fairly. Under the right conditions, this addition of other supports aside from the instructors can meet student needs and avoid the addition of other costly resources, such as an extra course tutor. However, it is important to keep in mind that casual peer support cannot replace all instructional support, especially in cases where some students require specialized help for specific situations. The institution must ensure the provision to the learners of the learning materials, direction, and tools necessary to succeed [2]. Despite these specialized considerations of more targeted faculty interventions, Jacklin \& Le Riche [17] insist that this paradigm shift where students become increasingly more involved in support can foster a culture able to fill the gap tutor, teacher and administrative support are unable to meet.

The Use of Support for Student Retention in Online Learning Universities. Palmer [2] observed the importance of satisfaction and linked student satisfaction intrinsically to student enrollment and success, student retention, faculty involvement in online learning, and program development and quality. Universities are continuously researching issues of student retention in order to reduce the dropout rate. The flexibility that online learning universities offer may contribute to a higher dropout rate among those types of universities [19], as some students may have the need for the structure [4] direction and dialogue found in the more traditional face-to-face universities. To support these online learners, Rovai's [as cited in 19] posits that universities can influence student persistence. This counters the misconception that student determination is completely out of the control of the universities. To support students' persistence and their success, universities could identify which students would benefit from greater support services and reduce their transactional distance [19]. Moore [8] discussed the role that dialogue plays in transactional distance, and subsequently student satisfaction. One way to reduce the transactional distance involves universities actively increasing dialogue before the beginning of the academic program, including providing students with a list of available university support services. Universities could then track and study the effectiveness of the use of these support services and identify which student support services have the greatest impact on improving student success and satisfaction within their program.

Nichols [19] noted that online learners are themselves more independent and may be under greater time restrictions. As such, they may not make the time to seek comprehensive support services which are offered to them. Because of the varying considerations around seeking and using support, it is important to discover and determine which type of services have the greatest impact, and which demographic will have the tendency to seek out administrative or instructor support services. Despite the need for increased attention to those who are more at-risk of dropout, students that are considered to be a low risk must also have support readily available should they need it.

In his study, Nichols [19] also emphasized that although student retention issues are vastly complex, the inclusion of support interventions - such as orientation courses, general messages of support and personal contact - attributed to an increase in student retention rates in the online learning program center at a Western university. In the study, he also found that students' acknowledgement of the role support services played in their retention was low. This finding concerning student acknowledgement of support services increases the need for exploration to identify strategies to improve and strengthen student retention.

There are theories that explore strategies for findings ways to improve and strengthen student retention. Herzberg [19] described a two-factor theory suggesting the view of support services in online learning can be explained by assuming that a factor being absent has a different effect from that same thing being present. In this case, the factor is student support in online learning. If support services are not sufficient it may have a negative impact on the positivity of student behavior toward online learning [2]. However, if the support provided to students is adequate, they may be less likely to attribute this success to the actual support services received or utilized. Support systems put in place that may not be as readily apparent might typically be under- appreciated in either setting. Without proper attention to the support systems that work and a concentrated effort toward understanding why they work, it is difficult to allocate further research or resources to improve them or introduce them to either face-to-face or online universities which are lacking their presence. This dichotomy highlights the increased need for the exploration of student perceptions of support services. Efficient student support services, both administrative and teacher faculty led, which are based on sound interventions will contribute positively to student retention and satisfaction [19]. The promotion of the success of interventions that have been proven to increase student support satisfaction may have the ability to increase the attraction of a university.

Difficulty Surveying Students Regarding Support. Most of the literature related to student satisfaction of their respective institutions is connected to the quality of instruction provided to them by the teaching faculty. This literature is more often than not used primarily by the teachers to improve the quality of teaching [20]. In a study by Beran et al. [20], students were surveyed regarding their level of satisfaction with support materials. The faculty felt that the data from the student responses regarding support materials were not convincing enough to change specific parts of their courses. Furthermore, knowledge of the ratings relating to the support materials were considered to be among the least useful to administrators. Such a reaction from the administrators and faculty can be associated with the traditional use of student ratings. For instance, student ratings tend more often to be used to identify quality of teaching, awards and recognition, faculty merit, promotion and tenure, but to not increase student support services [20]. The use of surveys should be tailored to identify the strengths and 
weaknesses of support provided to students by teachers and the administration. The data could then provide a comprehensive outlook on the current climate of support offered to a student by universities, and its subsequent impact on student satisfaction and retention. Improvement in the areas of weaknesses discovered would provide universities with direction on how to increase the attractiveness and maybe the retention rates of their universities.

\section{THEORETICAL FRAMEWORK}

Many theories have been developed to better understand students' learning experience in online learning as it relates to the differences implicated in the use of the new environments, technologies and processes. This study employed the theory of Transactional Distance, which aims to describe the universe of the teacher-student relationship when these entities are divided by space and/or time [8]. The theory has been adopted in online learning to identify proper techniques to reduce student feelings of isolation and to increase the interactive nature of courses delivered at a distance [8]. In online learning, transactional distance relates to the psychological and the communication spaces to be crossed between instructors and learners in an educational setting [8], which is seen as having a great impact on the student [21].

For this study, the theory of Transactional Distance was adopted because it places instructional dialogue and program structure at the forefront of the conversation [22], and it provides an ideal framework to compare face-to-face and online university student support [23] with a smaller number of participants. More specifically, Transactional Distance explores both the learner's autonomy and the learner's ability to interact with the instructor and the course material. However, the theory does acknowledge that the teacher-student relationship in a pedagogical context can be influenced by factors outside of the aforementioned attributes of the theory. In relation to this research study, Transactional Distance provides a framework to further examine the supports beyond solely instructor that contribute to student satisfaction [8].

\section{Methods, Data Sources AND Data ANAlysis}

Participants. The first author sent out a request for participants through his professional and social networks. Six individuals replied, but only five met the criteria of having studied at the undergraduate level at a face-to-face university prior to enrolling in an online undergraduate course at a Major North American University. The face-to-face university differed for all participants, but the Major North America University was the same. In all cases, the subject matter studied by the participants differed, ranging from nursing to computer science. Of the five participants, two were male and three were female. The ages of the participants ranged from twenty-six to twenty-seven. Participants were provided a consent form outlining the purpose and process of the study according to the guidelines of the first author's university. They were then asked to sign a consent form.

Instrument. The instrument used in the study was a ten-question interview questionnaire. The process of interviewing was semi-structured and allowed for deeper exploration of information based on the nature of the responses. The interviews lasted between fifteen and thirty minutes. The interview questions focused on student perceptions on the support they received from their respective universities and how it affected their feelings of satisfaction. Examples of the interview questions included:

- What methods of communication did you use to seek support from your instructor at the face-to-face post-secondary institution?

- How would you describe your experience with these communication methods?

- How did your methods of communication with your online instructor differ from your face-to-face instructor?

- When comparing both methods of instruction, face-to-face and online, which method did you find supported you best as a student when you needed help? Why?

Responses from the five interviews allowed the researchers to identify and explore situational problems in the context of educational differences in the various methods of delivery [24]. For the face-to-face university, students learned through a combination of in-class lectures, group work, and assignments while participating in at least one online course. For the online university, a learning management system was used to provide students access to the instructor. This access included online communication methods such as e-mail, web conferencing, and discussion forums. Interviews were analyzed using grounded theory which encouraged the researcher to develop a theory derived from the data [25].

Data Analysis. Interviews were recorded using a digital recording device and then transcribed by the first author. The transcriptions of the interview were then subjected to coding. The coding procedure uncovered common responses and feelings that the students expressed in their interviews. The data coding provided a system to refine the extensive data from the transcripts in to smaller and meaningful units to create categories and derive concepts related to the purpose of the study [26]. This refinement took place with the identification and frequency counting of reoccurring terms. Relevant terms were coded using the words or phrases with the highest frequency in the transcripts.

Upon completion of the coding process, the codes were compiled in a spreadsheet. The codes were then analyzed in phases.

The first phase was an analysis and coding of the individual experience of a participant in both education delivery methods. The codes were separated by instructional delivery methods: face-to-face and online learning. The first author discovered that common codes were used for identical topics and issues, but were not necessarily accompanied by the same sentiment. For example, issues surrounding the presence of an education community were prevalent, but often a sentiment in one instructional delivery context differed from that in the other instructional delivery context. Consequently, single codes were then subdivided in to a positive or negative sentiment column depending on the context of its occurrence. This subdivision provided a better 
description of the origin of the code and allowed the researcher to further understand the common experiences that the participants discussed.

The second phase of analysis separated the different experiences that students encountered within each method of educational delivery. The codes of the participants were drawn, and then separated in to a face-to-face coding group and an online group. This allowed the researcher to set up for the instructional delivery method comparison. Codes that could be classified in the same category were grouped together under the same code to eliminate redundancy. The total number of negative and positive codes was compiled to further differentiate between the nature of the experience noted by the participant. The codes were also grouped into similar categories dependent upon nature of the issue and the sentiment. Each category was then given a name based on the overarching theme it touched on. In total, four thematic groups were identified: Instructor Service and Support, Student Attitude, Auxiliary Support, and Course Design and Setup.

The second analysis was followed by a comparison of what the literature has observed in terms of support and the keys to higher levels of student satisfaction: the purpose of the study. This comparison was examined with regards to adequate support for the education delivery methods relating to the four dominant thematic categories identified in the first analysis above. The literature furthered the validation of the researcher's decision to classify and categorize the four main themes. Similar instances expressed by the participants were found throughout the described literature.

Finally, the last phase of analysis explored the variances of the level of student satisfaction between both educational delivery methods by comparing the similarities and differences of each. The coding, separation, analysis and synthesis of terms enabled the generation of overarching themes that encompassed common matters of all of the participants. Though not necessarily generalizable due to the low number of participants, the themes of the study encompassed common matters across all participants which illustrated the different supports students received and preferred in a face-to-face university and an online university.

\section{Results}

Semi-structured interviews revealed four overarching themes of how students felt about the support provided in each university. These themes included: instructor service and support, student attitude, auxiliary support, and course design and setup.

Instructor service and support. The frequency of the positive instructor service and support codes was higher in the face-to-face university than the online university. According to participants, instructor service and support had a greater effect on their levels of satisfaction in the online university. Factors like instructor interest in their students and timely responses increased student levels of satisfaction, while students who experienced delayed responses and a lack of interest from their respective instructors reported lower levels of support satisfaction. For example, in one participant's interview, they mentioned that they felt a high level of separation between themselves and the online institution when the attempt to obtain support took weeks to achieve. The instructor did not follow the agreed upon response timelines outlined at the beginning of the course. The level of separation this student experienced with their instructor could be described as a high level of transactional distance under Moore's [8] definition. The participant stated that this high level of transactional distance caused them to drop out of the online course. In contrast, another participant mentioned that they had received "very fast" support in their online course, which could be described as a low level of transactional distance. This low level of transactional distance contributed to their positive experience at the online university versus the negative one they mentioned they experienced at their face-to-face university. As a result of this support experience, they decided to enroll in more online courses at the online university and avoid face-to-face universities when possible.

Student attitude. The effect of a student's attitude towards an institution has been shown to have an impact on their desire to further their education. Participants, that attended the online university, reported negative emotions and high levels of stress because there were times they felt dissatisfied with the support they received. In one case, a participant returned to a face-to-face university to complete their education, feeling that the online university was unable to provide the timely support that they wanted and needed. Another participant expressed feelings of dissatisfaction with the online university but opted to continue due to the flexibility of the program.

Participant attitudes were affected by many factors in learning, especially when related to support. These factors included the ease of access of support, the cost of learning, as well as the experience that the participants faced during instruction. The manifestation of these factors had an impact on other factors around participant attitudes that included student experience, student motivation and, finally, student attrition. When the factors that influenced participant attitudes were positive, the resulting attitudes of the participants were positive. When the factors that influenced participant were negative, participants reported negative emotions and attitudes toward their respective institutions and in two cases led to participants withdrawing from their respective institutions.

Auxiliary support. The student population and diversity will continue to grow and universities will need to be proactive and adaptive with their support services [2], [14]. Face-to-face universities provide some of the participants with an easy accessible community of peers for support, while other participants prefer anytime, anywhere discussion forums that the online university offers. The forums include information from current and previous cohorts of the same course. Jacklin \& Le Riche [17] introduce the idea of including students in the responsibility of providing support to other fellow students to meet the increase demand and complexity of an online learning environment. They also insist that this paradigm shift, in which students become increasingly involved in support, will foster a culture that may fill the gaps that the instructor is unable to meet [17]. 
Two participants mentioned the role that discussion forums played in solving their questions throughout their online experience. In these situations, their peers provided the answers to their questions. To further Jacklin \& Le Riche's [17] point, two other participants discussed the importance of having a community of peers during their face-to-face courses and how the community increased the level of support they received and augmented their level of satisfaction overall.

This portion focuses on the differences in educational community and peer support among the different experiences had by participants. After reviewing the implications of auxiliary support in the transcripts, the support gaps that may be missing from an instructor can be closed by an institution's administration and fellow student peers. Jacklin \& Le Riche [17] disclose that students should become increasingly more involved in support in order to close the gaps for which a faculty does not have the time to attend to. An increase in peer-support lead to an increase two participants' sense of affiliation to the online. They felt that the online community positively attributed to support that allowed them to proceed without the necessity to contact their respective professors. The three other participants highlighted the importance of being a part of their respective face-to-face institutions and the absence of that feeling of belonging at the online university.

The administrations played important roles for two participants in the study. Involvement of administration was high for one participant in both face-to-face and online settings. Involvement of administration was high for another participant in online and face-to-face. This involvement of the administration helped both participants with the progression of their studies, contributed positively to their attitudes and reduced the work required by the students and their respective faculties to complete the courses.

Course design and setup. The environment and user experience of a course contribute to its level of attendance [19]. The inclusion of orientation sessions provided by the face-to-face university increased three participants' levels of satisfaction. Participants in the online university appreciated the design and setup of the online course in which they were able to progress at their own rate and access support when needed via discussion forum. This idea is reflected when two participants attended courses in which the course designs allowed the participants to complete the required learning activities, access timely support and complete the assessments with ease independently of the live access of their professor. The participants had the autonomy to dictate when and how quickly they would work on the learning activities for the course, access asynchronous help online through the use of the discussion forums and complete the exams remotely with the help of invigilators in their respective cities. Nichols [19] also mentions that support systems put in place that may not seem apparent might typically be under-appreciated in either setting. This possibility was apparent in one participant's interview as they seemed to only realize that various methods of support were put in place once they were highlighted by the interviewer. However, the online format is not ideal for all and left other participants feeling unsupported in situations where the user interface was difficult to navigate. Moore [8] mentions that the course design must stimulate, or at least maintain, the student's interest in what is to be taught, motivate the student to learn, and enhance and maintain the learner's interest. When one participant described their experience at the online university, they noted that the learning activities were designed without the use of several technologies which were available to online institutions. The design failed to include activities such as interactive online scenarios the student had noticed independently while using an outside resource for support with their computer programming course. This experience of the university using less than was readily available online contributed to a less than satisfactory-level experience and a requirement for them to seek additional support. This additional support was a feature they were unable to receive in a timely or adequate manner from the instructor, perhaps they could have been provided with the use of more modern technology. Significantly, they later described the online learning experience as the "anti-online experience."

\section{CONCLUSION}

This study demonstrated that though some participants were more satisfied with the support they received from the instructors at the face-to-face university, the flexibility of online learning in terms of time and space more significantly influenced their decision to continue attending an online university. The theory of transactional distance was used to as a framework to study students' perceptions of the support and their level of satisfaction.

There were several factors that influence students level of satisfaction with regards to support [7], the most important one discussed by the participants was the instructor's desire to show interest in the learning outcomes of the students and dedicating their time to help students overcome obstacles that may limit their ability to reach these desired outcomes. These factors highlighted the importance of regular instructor-student dialogue in student learning. Acknowledging the differences between an online and a face-to-face university, and understanding the effects of these two delivery approaches may help institutions provide a better learning environment by identifying the levels of dialogue, course structures, and strategies that maximize student support and improve student satisfaction as a result of instructor involvement. Similar to other online platforms such as Facebook's social media platform and Netflix's video streaming service, customer, or in this case student, satisfaction remains an important area of discussion related to the maturation process of the online learning environment. The effort placed on improving student satisfaction is in the best interests of public educators as the lack of satisfaction may have considerable repercussions including student attrition, hesitation to enroll in future programs, and an overall lack of student participation in their educational institutions [19].

Though limited by the number of participants, this study offers new insight on several factors that increase student satisfaction with regards to support, regardless of the delivery method. These factors were instructor service and support, student attitude, auxiliary support, and course design and setup. Further exploration of these factors can help 
universities offer attractive post-secondary programs that more effectively sustain student connection and reduce the level of transactional distance. We argue that it is important for instructors to understand the best ways to support student learning in both online and face-to-face environments. This more nuanced understanding will help to "build knowledge to support the quest for equitable educational opportunity...[as well as] (re)imagine and contribute to developing what public education can and must be for today's children, their families, and communities, and for the billions who will be inheritors of this earth" [16].

\section{REFERENCES}

[1] J. Roberts and E. Keough, Why the Information Highway? Toronto: Trifolium Books, 1995.

[2] A. Palmer, "Assessing student and faculty satisfaction in a master of counseling distance education paradigm," M.S. Thesis, Dept. Education, University of Lethbridge, Lethbridge, Alberta, Canada.

[3] A. W. Bates and G. Poole, "A framework for selecting and using technology," Effective Teaching with Technology in Higher Education, San Francisco, CA: Jossey Bass. 2003, pp. 75-105.

[4] X. Huang, A. Chandra, C. A. DePaolo, and L. L. Simmons, "Understanding transactional distance in web -based learning environments: An empirical study," British Journal of Educational Technology, vol. 47, no. 4, 2016, pp. 734-747.

[5] L. Murphy, M. Shelley, and U. Bauman. "Qualities of effective tutors in distance language teaching: Student perceptions," Innovation in Language Learning and Teaching, vol. 2, no. 12, pp. 119-136.

[6] R. Yilmaz and H. Keser, "The impact of interactive environment and metacognitive support on academic achievement and transactional distance in online learning," Journal of Educational Computing Research, vol. 55, no. 1, 2017, pp. 95-122.

[7] K. C. Ekwunife-Orakwue and T. L. Teng, "The impact of transactional distance: Dialogic interactions on student learning outcomes in online and blended environments," Computers \& Education, vol. 78, 2014, pp. 414-427.

[8] M. G. Moore, "Theory of transactional distance," Theoretical Principles of Distance Education, vol. 1, New York: Routledge, 1993, pp. 22-38.

[9] P. D. Umbach and M. R. Wawrzynski, "Faculty do matter. The role of college faculty in student learning and engagement," Research in Higher Education, vol. 46, no. 2, pp. 153-184, 2005.

[10] K. Phirangee and J. Hewitt, "Loving this dialogue!!!!-: Expressing emotion through the strategic manipulation of limited non-verbal cues in online learning environments" Emotions, Technology, and Learning, New York: Elsevier, 2016, pp. 69-85.

[11] J. C. Sherblom, "The computer-mediated communication (CMC) classroom: A challenge of medium, presence, interaction, identity, and relationship," Communication Education, vol. 59, no. 4, pp. 497-523, 2010.

[12] V. Dolan, "The isolation of online adjunct faculty and its impact on their performance," The International Review of Research in Open and Distributed Learning, vol. 12, no. 2, pp. 62-77, Feb. 2011.

[13] L. Murphy, M. Shelley, and U. Baumann, "Qualities of effective tutors in distance language teaching: student perceptions," Innovation in Language Learning and Teaching, vol. 2, no. 4, 12, pp. 119-136, 2010.

[14] R. Leclaire, "University enrollment continues to climb," Study Magazine.

[15] B. Fozdar and L. Kumar, "Mobile learning and student retention," International Review of Research in Open and Distance Learning, vol. 8, no. 2, 2007.

[16] D. L. Ball, C. O'Connor, and S. Wilson, "The dreams, possibilities, and necessity of public education," presented at 2017 Annual Meeting. 2017.

[17] A. Jacklin and P. Riche, "Reconceptualizing student support: From 'support' to 'supportive'," Studies in Higher Education, vol. 34, no. 7, pp. 49-70, 2005.

[18] A. Tait, "Planning student support for open and distance learning," Open Learning, vol. 15, no. 3, pp. 287-99, 2000.

[19] M. Nichols, "Student perceptions of support services and the influence of targeted interventions on retention in distance education," Distance Education, vol. 31, no. 1, pp. 93-113, 2010.

[20] T. Beran, C. Violators, D. Kline, and J. Riders, "The utility of student ratings of instruction for students, faculty, and administrators: A "consequential validity study", Canadian Journal of Higher Education, vol. 35, no. 2, pp. 49-70, 2005.

[21] R. Benson and G. Samarawickrema, "Addressing the context of e-learning: using transactional distance theory to inform design," Distance Education, vol. 30, no. 1, pp. 5-21, 2009.

[22] X. Huang, A. Chandra, C. A. DePaolo, and L. L. Simmons, "Understanding transactional distance in web-based learning environments: An empirical study," British Journal of Educational Technology, vol. 47, no. 4, pp. 734-747, June 2016.

[23] S. Benton, L. D. Li, A. Gross, W. H. Pallett, and R. J. Webster, "Transactional distance and student ratings in online college courses," American Journal of Distance Education, vol. 27, no. 4, pp. 207-217, 2013.

[24] J. Creswell, Research Design: Qualitative, Quantitative, and Mixed Methods Approaches, 3rd ed., Thousand Oaks, CA: Sage Publications Inc., 2009, pp. 173-202.

[25] K. Charmaz, Constructing Grounded Theory, Thousand Oaks, Calif: Sage Publications, 2010.

[26] J. True, M. Cendejas, K. Appiah, K., A. Guy, and R. Pacas, "Data coding and screening," University of California, Los Angeles, Los Angeles, 2008

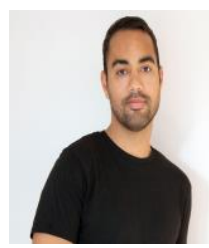

A. Després-Bedward was born in Ottawa, Canada on November 18,1987 . He is a doctoral candidate in curriculum studies at the Ontario Institute for Studies in Education at the University of Toronto in Toronto, Canada. He received his Master of Education in distance education from Athabasca University in Athabasca, Canada in 2014, and his bachelor of Science in human kinetics from the University of Ottawa in Ottawa, Canada in 2009.

He is a Special Projects Officer at the Canada School of Public Service in Ottawa, Canada. He has worked for this department since May 2014. Prior to this current occupation, he spent seven years working as a Course Developer and Learning Systems Analyst at the Department of National Defense. He recently published a book chapter with his colleagues entitled, Resourceful Instructors and Students: Overcoming Barriers to Integrating Mobile Tools In Iamlearning: Mobilizing And Supporting Educator Practice [e-Book]. His research interests include curriculum theory, mobile learning, engineering education, higher education, and education for sustainable development.

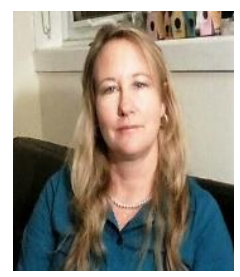

T. L. Avery is a graduate student in the Master of Arts, Curriculum Development and Leadership program at the Ontario Institute for Studies in Education (O.I.S.E) at the University of Toronto in Toronto, Canada. She is also pursuing the collaborative program with the Information School in Knowledge Media and Design at the same university. Ms. Avery was awarded a SSHRC grant in 2017 and continues to work on a research project around instructor pedagogy in graduate blended and online courses. Currently Ms. Avery is a Researcher for the Pepper Research team. Ms. Avery is also involved in a pilot study about gamification in a large undergraduate blended course. Prior to attending O.I.S.E., Ms. Avery directed an international charity headquartered in Antigua, W.I. She was also principal and founder of a K-12 private school which now operates a college scholarship placement program.

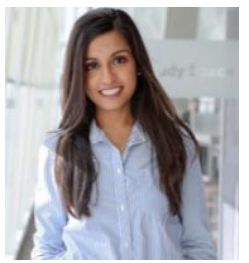

K. Phirangee was born in Trinidad and Tobago on August 30, 1985. She has a B.A., Hons in sociology (2008), a Bachelor of education in elementary education (2008), and a master of education focusing on educational/instructional technology (2012), from York University in Toronto, Canada. She also has a $\mathrm{PhD}$ in educational/instructional technology (2016) from the Ontario Institute for Studies in Education,

University of Toronto in Toronto, Canada. She is currently working as a Senior Researcher for the Pepper Research Team at the University of Toronto in Toronto, Canada, and an Instructional Designer at Ryerson University in Toronto, Canada. Her recent publications include: 1) A book chapter with her colleagues titled Resourceful Instructors and Students: Overcoming Barriers to Integrating Mobile Tools. In Iamlearning: Mobilizing And Supporting Educator Practice [e-Book], 2) a journal article with a colleague titled Othering in Online Learning: An Examination of Social Presence, Identity, and Sense of Community. In a special issue of Distance Education, 3) a journal article titled Students' Perceptions of Learner-Learner Interactions that Weaken a Sense of Community in an Online Learning Environment. In a special Issue of the Online Learning Journal. 